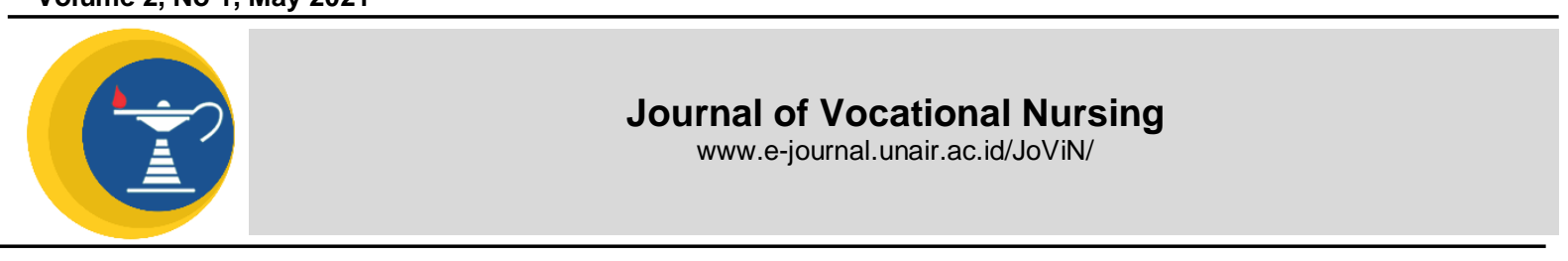

\title{
NURSING CARE FOR ACUTE PAIN IN POST-OPERATION FRACTURES
}

\author{
Ilkafah Ilkafah and Indah Dwi Lestari \\ Faculty of Vocational Studies, Universitas Airlangga
}

Research Report

\section{A B S T R ACT}

Introduction: Fracture is a condition which will cause interference with mobilization and pain in patients. In a fracture patient, the patient will be surgically operated or operated on. Complaints that often arise in patients due to after surgery is pain. Pain is a major nursing problem in fractures. The purpose of this study was to carry out nursing care for patients with acute pain in patients with Sinusra Radius Fracture Post Surgery in Dr. Soegiri Lamongan. Methods: This research used qualitative research case study approach. The research subject used was one patient with a nursing problem that is Acute Pain in Post Sinusra Radius Fracture Surgery. This study used 1 patient as a participant on 26 September 2019 to 28 September 2019 in Bougenvil 1 room Dr. Soegiri Lamongan. Data collection uses assessment by interview, physical examination, supporting examination and supported by other documentation. Data analysis with this research was carried out while still paying attention to research ethics. Results: The results obtained are acute pain nursing problems, with priority nursing actions efforts to overcome decreased pain in patients. After doing care for three days, there are decrease in pain scale as evidenced by the pain scale on the third day, the client improved with the original scale of 5 to 3. Conclusion: The conclusion from the research conducted found that deep breathing relaxation technique is one of the effective non-pharmacological pain management methods to reduce pain. To overcome the postoperative incident Sinus Radius Fracture, patients should take medication regularly, and control health services.

\section{ARTICLE INFO}

Received April 15, 2021

Accepted May 29, 2021

Online May 31, 2021

${ }^{*}$ Correspondence:

Ilkafah Ilkafah

*Email:

ilkafahbasar@gmail.com

\author{
Keywords: \\ Acute Pain, Nursing Care, Post \\ Operations Sinistra Radius
}

Fracture

\section{INTRODUCTION}

Fracture is a condition which will cause impaired mobilization and pain in the patient. In fracture patients, surgery or surgery will be performed to reconnect the broken bones. After post surgery is performed on the patient, postoperative fracture will experience a period after surgery that begins when the patient is transferred to the recovery room and ends with further revaluation (Uliyah \& Hidayat, 2011). The complaint that often arises in patients as a result of surgery is pain. Pain is the major nursing problem in fractures. Pain that arises due to tissue damage due to actual and potential incisions, pain occurs when it coincides with the disease process or coincides with the treatment process (Brunner \& sudarth, 2017).

Based on data from the World Health Organization (WHO), in 2017-2018 there were 5.6 million people died and 1.3 million people suffered fractures due to traffic accidents
(WHO, 2018). There were 1,775 people (3.8\%) who had fractured falls from the 14,127 sharp or blunt force trauma who had fractured as many as 236 people (1.7\%). In East Java, the incidence of fracture is $6.0 \%$ (RISKESDAS, 2018). Of all the fractures that came to Dr. General Hospital. Soegiri Lamongan, Indonesia in 2019 shows that $79.5 \%$ (Nugraha \& Adianto, 2019). In the case of postoperative fracture patients, they experience pain due to the breakdown of tissue in the skin. If the pain in postoperative patients is not handled immediately, it will cause the patient to experience anxiety, immobilization, avoiding a decrease in attention span, stress and tension which will cause physical and psychological responses (Pratintya, 2014).

To prevent this from happening, the role of nurses and health workers needs to be taken into account for pain management and pharmacological management. Pain management is a part of medical science 
related to pain relief (Pratintya, 2014). Nursing care for pain management can be done with distraction and relaxation techniques. Based on the description above, considering the importance of providing a sense of comfort for pain, to conduct research / case studies on Nursing Care for patients with Acute Pain Post Sinistra Radius Fracture Surgery in Bougenvil 1 Room General Hospital Dr. Soegiri Lamongan.

\section{MATERIALS AND METHODS}

This type of research is qualitative research which includes an intensive study of a single research unit, for example clients, families, groups, communities, or institutions. The case study design depends on the situation of the case but still takes into account the research factors at the time this research was conducted in the Bougenvil 1 room Dr. Soegiri Lamongan. Data collection techniques used in the preparation of the Final Study Report are: interviews, observation, documentation. The data validity test emphasizes validity and reliability. The participant in this case study is Mr. A in Bougenvil 1 room Dr. Soegiri Lamongan.

\section{RESULTS AND DISCUSSION Assessment}

Assessment of patient identity, at the time of assessment of the client with a grinning face due to pain after surgery, in this case there is a gap between the case review and the literature review. Based on the case review on Mr. A suffered a fracture of his left radius 78 years old with a man with acute postoperative pain due to tissue breakdown in the skin. Whereas in a literature review according to Wahid (2013), it was explained that the incidence of having a radius fracture due to traumatic injury, generally over 45 years of age and radius fracture can occur in women and men, but this disease is more risky for the elderly.

In theory, there is a case of fracture, whereas in the case of acute postoperative pain in the client, it is caused by a break in the tissue in the incised skin so that further nursing is carried out to deal with the pain. In the main complaint, the writer also found a match between case review and literature review, where the main complaint that the patient felt was left hand pain. Meanwhile, in the literature review according to the postoperative theory according to Wahid (2013), which states that the main complaint in radius fracture patients is pain. This is because the skin tissue is severed, causing pain. In the assessment of the history of the disease there is now a correspondence between a case review and a literature review. In the case review, the patient said the pain from the surgery scar was on his left hand, after having an accident due to falling from a chair while watching television at 19.00 WIB. Pain feels like aching and stabbing, pain is felt when moving and pain is reduced when resting, pain scale $5 . \ln$ a literature review according to (Wahid, 2013), it is explained that the present disease history is an assessment which is described from the main complaint is acute pain with using PQRST. This is because the pain felt by patients after surgery is basically the same depending on the patient's response to pain resistance.

In the family history of disease, the authors also found gaps between case reviews and literature reviews. Based on the history in the case review, the patient does not have a family who has an inherited bone-related disease. While the theory according to Wahid (2013) states that one of the causes of radius fracture is a history of decreased disease associated with bone diseases, such as diabetes, osteoporosis, and bone cancer. In the psycho, socio and spiritual history there is a correspondence between case reviews and literature reviews. In the case review, the patient feels pain and feels sad about the illness he is suffering from, because he can only lie down and cannot do activities but the relationship with family, nurses, doctors and other patients is good, the patient is also a Muslim who is devout to worship. Meanwhile, according to the literature review according to Wahid's theory (2013), it explains that the patient's anxiety about the disease he is suffering from. This is because patients think about curing their illness, but patients always pray to Allah for their recovery.

The pattern of daily needs (ADL). In the nutritional pattern there is an agreement between case reviews and literature reviews. The patient's case review after surgery is fasted until the patient has flatus, after which the patient's flatus eats and drinks gradually. Meanwhile, according to the theoretical literature review according to Lukman \& Ningsing, (2011), that patients with postoperative radius fracture must be fasted first until they experience flatus. This is if the patient is already flatus, it is advisable to eat and drink gradually, consume more nutrients than daily needs, eat low protein foods and others to help the healing process.

In the elimination pattern, there is a match between literature review and case review. In the case review, the patient while in the hospital BAK was normal with urine \pm 1500 
/ day, dark yellow color and CHAPTER $1 \mathrm{x}$ a day with a soft consistency, yellow color, characteristic odor. In a literature review according to Lukman \& Ningsing (2011), in the patient elimination pattern, constipation occurs due to the effect of anesthesia, while urine elimination using a catheter in urine output may not occur. This is because the effect of anesthesia has disappeared so that the patient does not experience disturbances in the elimination pattern of both BAK and BAB.

The pattern of rest there is a match between case reviews and literature reviews. In the case review, the patient had poor sleep and was often awakened by the pain. Meanwhile, according to a theoretical literature review according to Lukman \& Ningsing (2011), patients with fractures need rest can be disturbed. This is because the patient is bothered by the pain that is felt at rest.

In the personal hygine pattern there is a match between case reviews and literature reviews. In case reviews, patients with fractures tended to pay less attention to personal hygiene. Meanwhile, according to the theory of Lukman \& Ningsing (2011), a case review, fracture patients also tend to pay less attention to personal hygiene. This is because patients with fractures do not pay attention to personal hygiene due to surgery scars that are not allowed to be exposed to water, so personal hygiene needs are assisted by their families.

In the activity pattern there is a match between case reviews and literature reviews. In a case review of fracture patients, all activities are assisted by other people or by their families. According to the theory of Lukman \& Ningsing (2011), in radius fracture patients all their activities are also assisted by their families.

On physical examination, there is a correspondence between case review and literature review. In the case review the patient was performed a head to toe examination from head to toe. The left upper limb is painful and cannot move freely attached to the cast and arm sling aid. While a case review with theory according to Wahid (2013), fracture patients have limited movement. This is because after an accident the strength of his hand muscles began to decrease and due to the installation of a cast, the patient could not move freely.

In supporting examination, the writer also found a match between case review and literature review. In the case review, a rongent photo examination was obtained. While a case review according to theory according to (Wahid, 2013), fracture patients are subjected to rongent photo examinations to get a 3 - dimensional picture of the difficult bone condition and position. This is because the Xray examination can determine the location / extent of the fracture and determine the diagnosis.

\section{Nursing diagnoses}

In nursing diagnoses there is an agreement between literature review and case review. In a literature review, the radius of the left according to (SDKI, 2017) is that acute pain is associated with severed skin tissue (D.0077), while according to the case review, acute pain is associated with severed skin tissue (D.0077). This acute pain can lose control of the body so that it can lead to disruption in activities.

Acute pain is the most important nursing problem, due to postoperative pain due to the incision, so that the skin tissue is cut off, if not treated immediately, the client will be anxious, lose body control, and the pain will increase. So that the authors take the acute pain nursing diagnosis as the main priority because it refers to the client's condition.

\section{Nursing Interventions}

In the postoperative case nursing intervention has the goal to solve the problem in the client with the specified time when the client is hospitalized with acute pain nursing problems, in that case there is a gap between the case review and literature review. From the literature review, the criteria for postoperative acute pain results according to SLKI (2017), namely the ability to complete activities increases, pain complaints decrease, grimace decreases, sleep difficulties decrease, and sleep patterns improve. And the action plan according to SIKI (2017) is pain management (I.08238) Observation: 1) Identification of location, characteristics, duration, frequency, quality, pain intensity, 2) Identification of pain scales, 3) Identification of non-verbal pain responses, 4) Identification of factors that aggravate and relieve pain, 5) Identify knowledge and beliefs about pain, 6) Identify cultural influences on pain response, 7) Identify the influence of pain on quality of life, 8) Monitor the success of complementary therapies that have been given, 9) Monitor side effects, Therapeutic: 1) use of analgesics, 2) Control the environment that aggravates the pain, 3) Facilitate rest and sleep, 4) Consider the type and source of pain in the choice of pain relief strategies, Education: 1) Explain the causes, periods and triggers pain, 2) Explain pain relief strategies, 3) Encourage independent pain monitoring, 4) Encourage proper use of analgesics, 5) Teach non- 
pharmacological techniques for to reduce pain Collaboration: 1) Collaboration of analgeic administration if necessary.

From a case review on nursing diagnoses, acute pain is associated with severed skin tissue with the criteria of increased activity results, decreased pain, a cheerful face, decreased sleep difficulties, and improved sleep patterns. Meanwhile, from the nursing plan, namely: Observation: 1) Identify the location of the pain 2) Identification of the pain scale for $3 \times 3$ ) Identification of pain knowledge and beliefs 4) Monitor drug side effects. Therapeutic: 1) Facilitate rest and sleep. Education: 1) Explain the causes of pain triggers, 2) Encourage independent pain monitoring 3) Teach non-pharmacological techniques to reduce pain. Collaboration: 1). Collaboration of analgesics. This is so that postoperative acute pain with severed skin tissue is a top priority diagnosis, because it is in accordance with the patient's condition. And in the intervention make changes to the client because the client can and understand what has been said and the client is cooperative in nursing actions so that within three days the intervention is stopped because the client has improved and the client scale decreases from 5 to 3.

\section{Nursing Implementation}

The author finds a match between literature review and case review. In a case review when nursing actions were carried out, implementation was carried out in accordance with the intervention measures according to client needs with postoperative acute pain. The scale decreased to 3 on the third day. The management of nursing actions is carried out in accordance with the plan that was made from September 26, 2019 to September 28, 2019 and all actions taken on patients are documented in nursing records. At this stage of implementation the authors carry out nursing care in accordance with the plans that have been made in the intervention. The author finds a match between literature review and case review. In case reviews when nursing actions were carried out, implementation was carried out in accordance with the intervention. The first day of nursing was carried out according to the intervention. In patients, implementation carried out in its implementation is adjusted to the priority of action. In a case review review of acute pain nursing diagnoses.

The second to third day of nursing was carried out according to the intervention and on the third day the patient was discharged and then given a discharge planning. This is evidenced by the theory of Mubarak, W. I., Cahyatin, N., \& Susanto, (2015) in the diagnosis of acute pain related to the loss of skin tissue integrity which has been carried out according to the intervention for 3 days. This is because the patient is cooperative, making it easier for the author to carry out an implementation that aims to cure patients with decreased pain.

\section{Nursing Evaluation}

In the evaluation, the writer monitors the client's condition with the actions that have been taken to find out whether there has been any change in the client, in this case the writer finds a match between the literature review and the case review. In trouble that arose to Mr. A is a diagnosis of acute pain associated with severed skin tissue, nursing care measures for 3 times 24 hours with the criteria of increased activity results, decreased pain, cheerful face, decreased sleep difficulties and improved sleep patterns. On the first day the goal has not been achieved because the patient still feels pain on a scale of 5 . On the second day, it is found that the patient says the pain is slightly reduced and the face is a little cheerful because the client is cooperative in nursing actions on a scale of 4 so that the intervention is continued because of the moderate pain scale. On the third day, the client looked relaxed with a pain scale of 3 or mild pain. The results of the goal are achieved, the client is obedient in nursing actions and the intervention is stopped because the client is getting better, can sleep soundly, and the pain is reduced. According to Nursalam's theory (2012), evaluation is carried out to identify the extent to which the goals of the plan have been achieved or not. This is because during the third day of evaluation the patient felt the pain reduced, the face relaxed, and the sleep pattern improved then the patient was sent home on the third day because the nursing action given by the client improved with discharge planning, that is, if the pain recurred in the future, do relaxation techniques, recommending control patients routinely to prevent complications, advising to take medication in a timely manner, do not take traditional medicines and vitamins without doctor's instructions, if you feel any side effects from the drug, check immediately to the hospital, maintain a doctor-recommended diet such as eating - low protein foods and others to aid the healing process.

\section{CONCLUSION}

The conclusion from the research conducted found that deep breathing 
relaxation technique is one of the effective non-pharmacological pain management methods to reduce pain. To overcome the postoperative incident Sinus Radius Fracture, patients should take medication regularly, and control health services.

\section{REFERENCES}

Brunner, \& sudarth. (2017). Surgical Medical Nursing. Jakarta: EGC.

Lukman, \& Ningsing, N. (2011). Nursing Care for Clients With Musculoskeletal System Disorders. Jakarta: Salemba Medika.

Nugraha, \& Adianto, A. (2019). EPIDEMIOLOGY OF FRACTURES AND DISLOCATIONS IN CHILDREN. Folia Medica Indonesiana, 53, 81- 85.

Nursalam. (2012). Nursing Process and Documentation of Concepts and Practices. Jakarta: Salemba Medika.

Pratintya, D. A. (2014). Warm Compress Reduces Osteortritis Joint Pain in the Elderly. Journal of Midwifery and Nursing.

RISKESDAS. (2018). Basic Health Research Report. Rosyidi, K. (2013). Musculoskeletal. Jakarta: Trans Info Medika.

SDKI. (2017). Indonesian Nursing Diagnosis Standards. Jakarta: PPNI.

SIKI. (2017). Indonesian Nursing Intervention Standards. Jakarta: PPNI.

SLKI. (2017). Indonesian Nursing Output Standards. Jakarta: PPNI.

Uliyah, \& Hidayat. (2011). Introduction to Nursing. Jakarta: Salemba Medika.

Wahid. (2013). Nursing Care With Musculoskeletal System Disorders. Jakarta: Sagung Seto.

WHO. (2018). Global Journal Of Medical Research. Global Journal Of Medical Research. 